\title{
Article \\ Experimental Study of Thermal Properties and Dynamic Viscosity of Graphene Oxide/Oil Nano-Lubricant
}

\author{
Ramin Ranjbarzadeh ${ }^{1, *}$ and Raoudha Chaabane ${ }^{2}$ (D) \\ 1 Department of Civil, Constructional and Environmental Engineering, Sapienza University of Rome, \\ Via Eudossiana 18, 00184 Rome, Italy \\ 2 Laboratory of Thermal and Energetic Systems Studies (LESTE), National School of Engineering of Monastir \\ (ENIM), University of Monastir, Monastir 5000, Tunisia; raoudhach@gmail.com \\ * Correspondence: ramin.ranjbarzadeh@uniroma1.it
}

Citation: Ranjbarzadeh, R.;

Chaabane, R. Experimental Study of Thermal Properties and Dynamic Viscosity of Graphene Oxide/Oil Nano-Lubricant. Energies 2021, 14, 2886. https://doi.org/10.3390/ en14102886

Academic Editor: Hussein A

Mohammed

Received: 7 March 2021

Accepted: 10 May 2021

Published: 17 May 2021

Publisher's Note: MDPI stays neutral with regard to jurisdictional claims in published maps and institutional affiliations.

Copyright: (c) 2021 by the authors. Licensee MDPI, Basel, Switzerland. This article is an open access article distributed under the terms and conditions of the Creative Commons Attribution (CC BY) license (https:// creativecommons.org/licenses/by/ $4.0 /)$.

\begin{abstract}
This experimental study was carried out based on the nanotechnology approach to enhance the efficacy of engine oil. Atomic and surface structures of graphene oxide (GO) nanoparticles were investigated by using a field emission scanning electron microscope and X-ray diffraction. The nano lubricant was produced by using a two-step method. The stability of nano lubricant was analyzed through dynamic light scattering. Various properties such as thermal conductivity, dynamic viscosity, flash point, cloud point and freezing point were investigated and the results were compared with the base oil (Oil- SAE-50). The results show that the thermal conductivity of nano lubricant was improved compared to the base fluid. This increase was correlated with progressing temperature. The dynamic viscosity was increased by variations in the volume fraction and reached its highest value of $36 \%$ compared to the base oil. The cloud point and freezing point are critical factors for oils, especially in cold seasons, so the efficacy of nano lubricant was improved maximally by $13.3 \%$ and $12.9 \%$, respectively, compared to the base oil. The flash point was enhanced by $8 \%$, which remarkably enhances the usability of the oil. It is ultimately assumed that this nano lubricant to be applied as an efficient alternative in industrial systems.
\end{abstract}

Keywords: experimental study; nano-lubricant; thermal conductivity; dynamic viscosity; flash point; cloud point; freezing point

\section{Introduction}

Today energy demand is increasing, so the issue of optimizing and improving the efficacy of energy systems is a critical matter. The industry requires high-efficiency lubricating and cooling fluids. A new technique to improve the lubrication and thermal properties of fluids is the use of nanotechnology [1,2]. Oils are extensively used as lubricants and coolants for lubrication and heat transfer in various industries. The most critical oil applications for engines include lubricating at both high and low temperature, reducing wear across multiple moving parts, cooling of moving parts, and so on. Therefore, the viscosity and thermal conductivity of the oil are critical properties that must be considered because viscosity directly impacts both pumping power and pressure drop; in addition, higher thermal conductivity means more excellent and better heat transfer performance [3-5]. Furthermore, the performance of the oil at temperatures close to zero and high temperatures is essential.

Nano lubricants are among the newly emerged and evolved technologies that have drawn the attention of researchers for utilization in lubrication and heat transfer systems due to their unique thermophysical properties. Nano lubricants are a class of new types of fluids. The stability of nano lubricant and oil performance under various situations and very high and low temperatures are among the most critical points for achieving a functional nano lubricant for better understanding lubrication and heating systems [6-8]. 
Nano lubricants are a key component in the industry, as they improve the performance of the surfaces affected and engine efficiency, besides, reduce fuel consumption and maintenance costs $[9,10]$. Today, many lubricants with varying properties are produced for various mechanical systems, including internal combustion engines (ICEs).

Friction in mechanical systems is a leading cause of energy loss [11,12]. The use of lubricants is an efficient strategy to reduce friction and excess heat in mechanical systems. Therefore, improving the properties of oils conserves energy and inhibits its loss in systems [13-15]. The following sections cover some results obtained from the previous studies.

Timofeeva et al. [16] investigated the thermophysical properties of $\mathrm{SiO} 2 /$ thermal oil nano-lubricant such as thermal conductivity, density, specific heat capacity and viscosity under the influence of variations in temperature and volume fraction. Cationic surfactant was used to disperse the nanoparticles in the base fluid. The results showed that the surfactant and silica nanoparticles improved the thermal conductivity of the oil. Dynamic viscosity of the nano-lubricant was increased depending on the volume fraction of the nanoparticles and the quantity of surfactant. However, no results were reported on the chemical properties of this surfactant over the base oil.

Deepak and Ram [17] studied the effect of using Titanium oxide nanoparticles on an SAE 20W-40 oil and a vegetable oil. They examined various properties of nanoparticles such as viscosity, flash point and fire point. The results showed an increase in the viscosity of nano lubricant compared to base oils, which is not a positive result. Furthermore, the flashpoint and fire point of non-vegetable base oil improved, respectively, by $12.73 \%$ and $12.20 \%$.

Ilyas et al. [18] studied nano-oils containing alumina nanoparticles in a thermal oil. The range of oil volume fraction was from $0.5 \%$ to $3 \%$ by mass. The stability of nanofluids was investigated under varying conditions. The rheological behavior of nanofluids was examined at high shear rates. The thermal conductivity and specific heat capacity of the nano lubricant were measured. According to the results, a remarkable improvement occurred in the thermal properties of oils containing alumina nanoparticles.

Ma et al. [19] experimentally investigated the effect of adding zinc oxide nanoparticles to engine oil for improving its properties. They studied different properties, namely dynamic viscosity, cloud, freezing and flash points. The results show that the viscosity of nano-oil increased to 25.3\%; however, this is not a positive achievement. Other oil properties, such as cloud point, freezing point and flash point, have been improved to 22.2, 19.4 and 7.2 percent, respectively.

Ahmadi et al. [20] studied the effect of MWCNT nanoparticles on the properties of engine oil in different volume fractions. Viscosity, thermal conductivity, combustion point and pour point were tested as four quality parameters impacting the oil efficacy. According to the results, thermal conductivity and combustion point of nano lubricant with a volume fraction of 0.1 were improved, respectively, by $13.2 \%$ and $6.7 \%$ compared to the base oil. Furthermore, the pour point in the volume fraction of 0.2 was improved by $3.3 \%$. The viscosity of the nano-oil was further increased due to the tubular structure of the nanoparticles.

The different characteristics of lubrication, heat transfer capacity and oil efficacy in systems at hottest and coldest temperatures are leading factors, which can influence power-pumping, electricity consumption by the system, usage limits and system operating range. Therefore, it is crucial to achieving a nano lubricant with suitable viscosity and higher thermal performance as an alternative for the base oil. For reaching an applied nano-oil with higher efficiency in systems, it is essential to entirely study parameters, such as thermal conductivity, viscosity, flash point, cloud point and freezing point. It is not sufficient to study only one or two parameters separately. This study uses Graphene oxide nanoparticles to enhance oil performance. In this study, characterization of nanoparticle, nano lubricant stability, thermal conductivity, dynamic viscosity, flash point, freezing point and pour point of SAE 50 oil at different volume fractions were evaluated. 


\section{Experimental}

\subsection{Materials and Methods}

Graphene oxide is a high potential nanoparticle. It has high thermal conductivity, high specific surface area (SSA), hydrophilicity, insolubility and low density. This experimental research was carried out using graphene oxide nanoparticles. They were purchased from US Research Nanomaterials Inc. for characterization of the surface and atomic structure using FESEM, TEM and XRD. The physical properties of graphene oxide nanosheets are presented in Table 1. These properties were introduced by the sealer office.

Table 1. Physical properties of graphene oxide nanosheets.

\begin{tabular}{cc}
\hline Physical Property & Value \\
\hline Appearance color & Black \\
Morphology shape & Nanosheet \\
Diameter $(\mu \mathrm{m})$ & $\sim 2$ \\
Purity $(\%)$ & 99.5 \\
density $\left(\mathrm{kg} / \mathrm{m}^{3}\right)$ & $\sim 1000$ \\
Thickness $(\mathrm{nm})$ & $3.4-7$ \\
Number of layers & $6-10$ \\
\hline
\end{tabular}

FESEM tests were performed using TESCAN-MIRA III. The FESEM test analyzed the morphology and structure of graphene oxide nanoparticles. The FESEM image in Figure 1 shows the planar structure of graphene oxide nanoparticles. Graphene Oxide particle has a one nano dimension and 2D microscale. The physical structure of a particle depends on the method of synthesis possess.

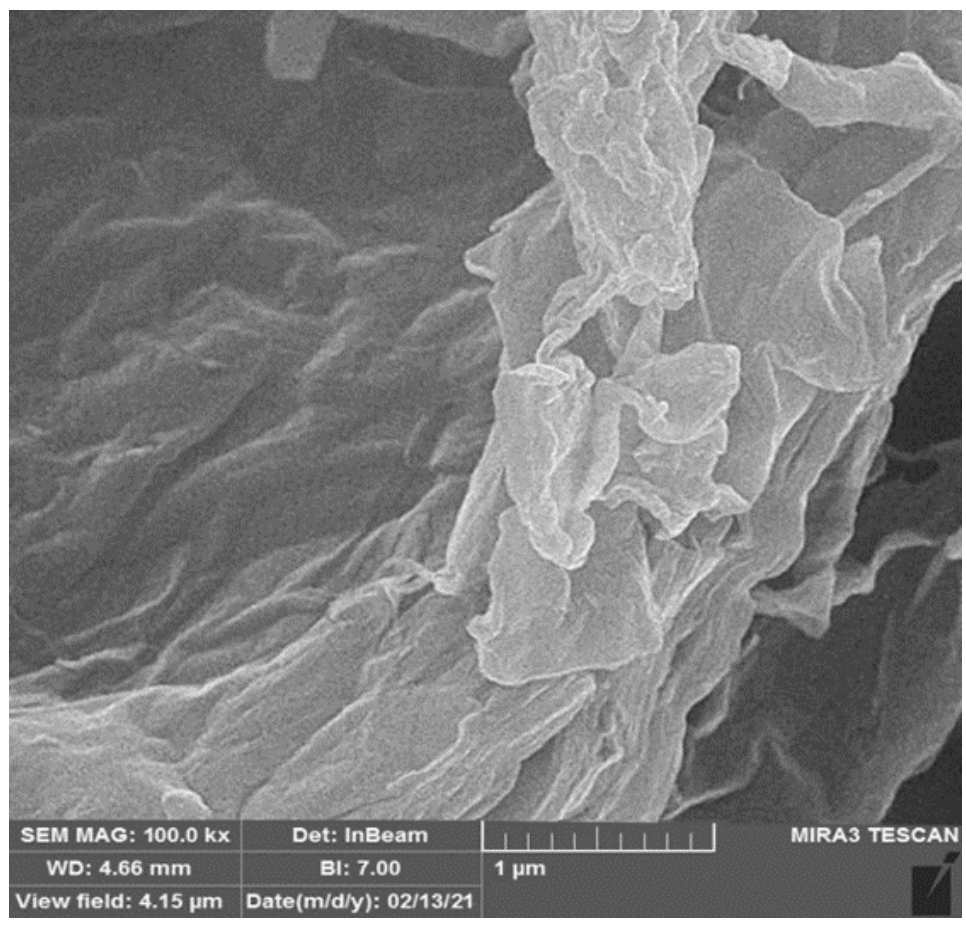

Figure 1. FESEM of graphene oxide nanoparticles.

Scanning transmission electron microscopy (TEM) test was used to determine the structure of nanoparticles in detail. The analysis was carried out using the PHILIPS EM device, $100 \mathrm{Kv}$, manufactured by Netherlands. The obtained result is presented in Figure 2. Surface structure of nanoparticles are observed. The figure shows that nanoparticles have a sheet structure. 


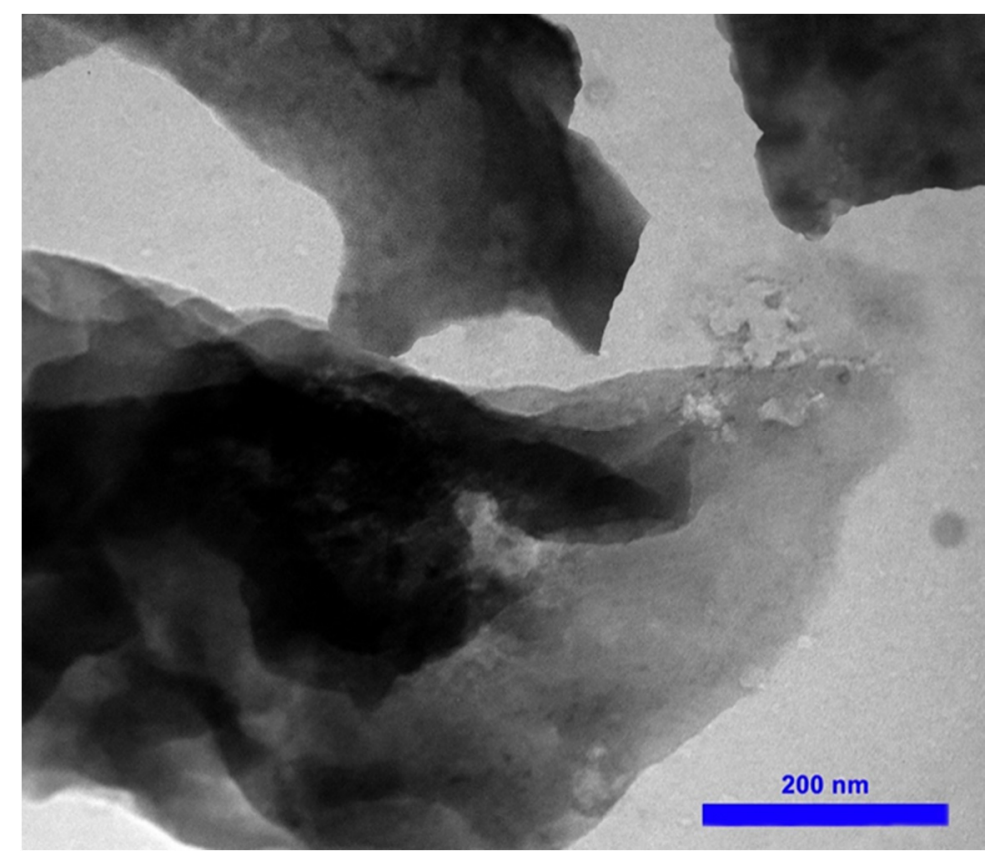

Figure 2. TEM of graphene oxide nanoparticles.

Normal XRD test was performed using PHILIPS-PW1730. The scan was conducted from 10 to 90 degrees. Step size and time per step were used 0.05 degrees and $1 \mathrm{~s}$, respectively. The XRD analysis was carried out to investigate the crystal structure of graphene oxide nanoparticles. This analysis is also known as the Bragg formulation of X-ray diffraction. The XRD image of graphene oxide nanoparticles is shown in Figure 3. The atomic structure of graphene oxide nanoparticles is confirmed by the peaks generated. The peaks in graphene oxide nanoparticles were seen at $11.15^{\circ}$ and $42.5^{\circ}$. The results of the XRD test presented are similar to the results of previous studies [21].

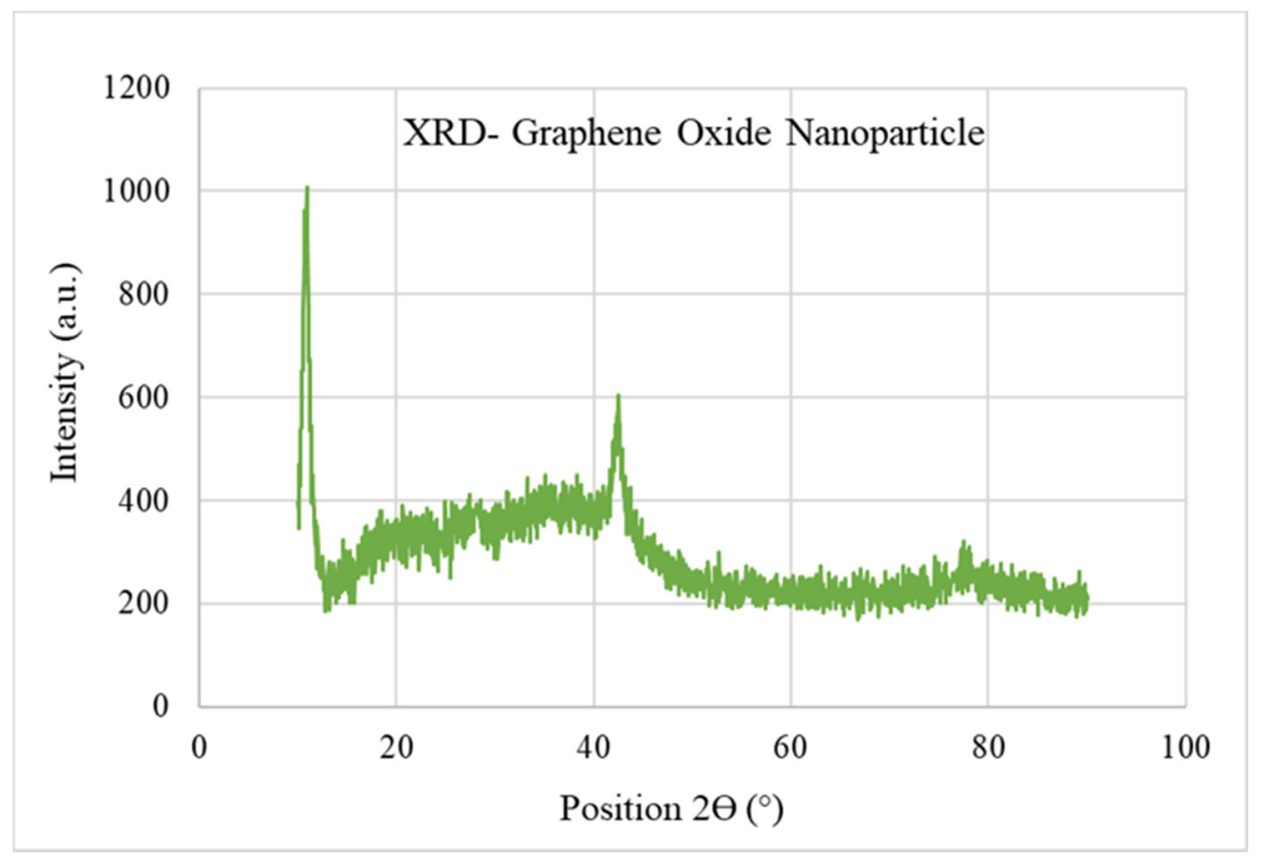

Figure 3. XRD of graphene oxide nanoparticles. 
The engine oil used in this study was of SAE 50 type provided by Behran Oil company. Table 2 presents the oil specifications according to the manufacturer's certification. The main thermophysical parameters of the oil are reported in the table below.

Table 2. Characteristics of SAE 50 engine oil.

\begin{tabular}{cc}
\hline Characteristic & Value \\
\hline Kinematic viscosity at $100{ }^{\circ} \mathrm{C}$ & $1.8 \times 10^{-5}\left(\mathrm{~m}^{2} / \mathrm{s}\right)$ \\
Viscosity Index (VI) & 90 \\
Flash point & $246\left({ }^{\circ} \mathrm{C}\right)$ \\
Pour point & $-9\left({ }^{\circ} \mathrm{C}\right)$ \\
Total base number (TBN) & $4.1(\mathrm{mg} \mathrm{KOH} / \mathrm{g})$ \\
Density at $15^{\circ} \mathrm{C}$ & $906\left(\mathrm{~kg} / \mathrm{cm}^{3}\right)$ \\
Specific heat capacity & $1900\left(\mathrm{~J} /\left(\mathrm{kg} \cdot{ }^{\circ} \mathrm{C}\right)\right)$ \\
\hline
\end{tabular}

\subsection{Preparation of Nano Lubricant}

The method of preparing nanofluids influences the quality of dispersed nanoparticles in the base fluid. It is crucial to prevent the agglomeration of nanoparticles during the preparation process [22,23]. Instability and accumulation due to the intermolecular forces in nanoparticles cause variations in the thermophysical properties of nanofluids [24].

In this study, nano lubricant was produced by the two-step method. For dispersing the particles, magnetic processes and ultrasonic waves were used. The nanoparticles mass for different volume fractions was calculated using Equation (1). The nanoparticles mass also base oil for preparing nano lubricant are reported in Table 3. However, more volumes were used to measure both the freezing point and flash point.

$$
\varphi(\%)=\frac{m_{G O}}{m_{G O}+m_{\text {Oil }}} \times 100
$$

Table 3. Nanoparticles mass and oil used to prepare $55 \mathrm{~mL}$ of nano-lubricant for each sample.

\begin{tabular}{cccc}
\hline Sample & Solid Volume Fraction $(\%)$ & $m_{G O}(\mathrm{~g})$ & $m_{\text {Oil }}(\mathrm{g})$ \\
\hline 1 & 0.00 & 0.000 & 49.83 \\
2 & 0.10 & 0.055 & 49.77 \\
3 & 0.25 & 0.137 & 49.69 \\
4 & 0.50 & 0.275 & 49.55 \\
5 & 1.00 & 0.550 & 49.28 \\
\hline
\end{tabular}

Nanoparticles were mixed for an hour in the base oil using the IKA C-MAG HS7 digital magnetic stirrer. The mixture of nanoparticles and base oil was subjected to ultrasonic waves for $60 \mathrm{~min}$ to homogenize and break up the lumps of particles. The Hielscher UP400St Ultrasonic Processor ( $400 \mathrm{~W}, 24 \mathrm{kHz}$ ) was used intermittently. An photograph of the nano lubricant samples is presented in Figure 4.

\subsection{Measurement of Thermal Conductivity}

The thermal conductivity of nano lubricant was measured using the transient hot-wire method (THWM) and according to ASTM D2717-95 standard. In this research KD2-Pro thermal property analyzer (Decagon Device, USA) was used. Thermal conductivity was measured under varying temperature conditions ranging from $35^{\circ} \mathrm{C}$ to $75^{\circ} \mathrm{C}$. The $\mathrm{KS}-1$ sensor was used for measurement and the temperature bath (model WNB 7 Memmert) to stabilize the temperature was used. According to the certificate of the KD2-Pro thermal property analyzer, the results measure by the KS-1 sensor can have a maximum of $5 \%$ error. At first, the accuracy of the analyzer was cheeked by using Glycerin verification standard and also pure water. Secondly, the temperature bath and thermal property analyzer have been run and, for measuring, we must wait to find a stable temperature and isothermal 
situation in the system. In this research, every sample was measured at least three times and the error was calculated. In Figure 5, experimental setup is presented.

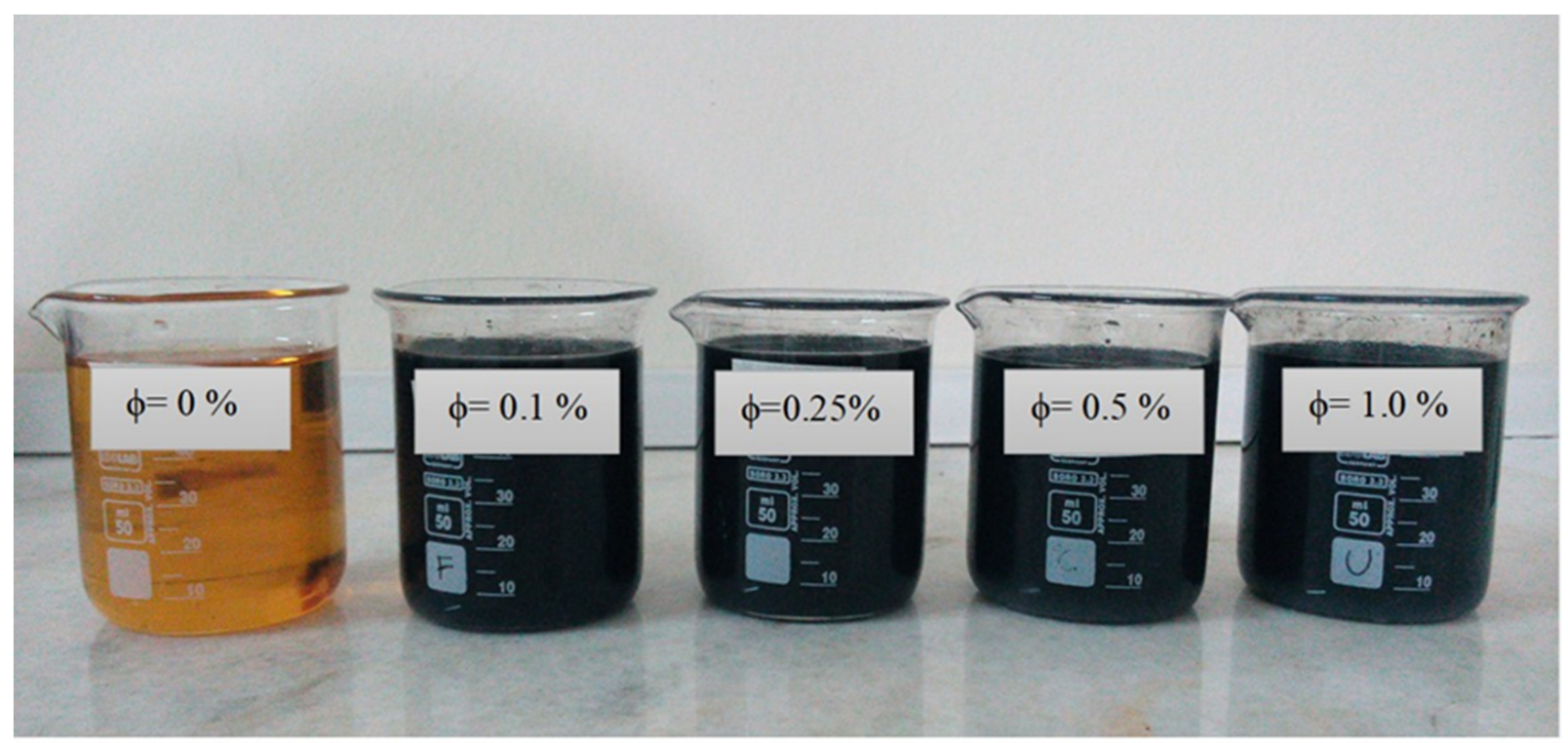

Figure 4. Nano lubricant samples.

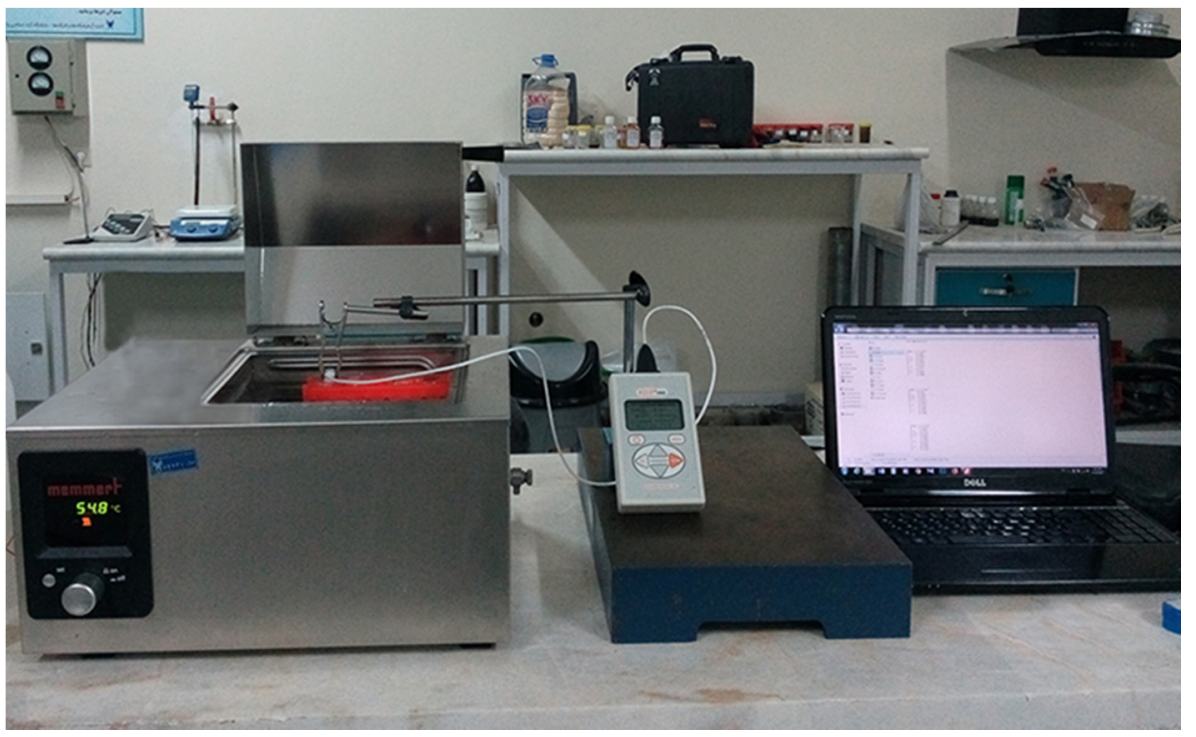

Figure 5. Experimental system for measuring thermal conductivity.

\subsection{Measurement of Viscosity}

Viscosity was measured according to the ASTM D789 standard. Brookfield Rotational Viscometer (DV2EXTRA-Pro) with a small sample adaptor was employed to measure the viscosity of different nano lubricant samples. During the measurement, the spindle speed and the allowable torque range were adjusted from 10 to 90; this range is recommended for the Brookfield viscosimeter. Viscosity is related to torque because the viscosity is typically measured with the reaction torque on the motor. Therefore, the viscous drag on the immersed spindle and the viscosity of the fluid are correlated. The accuracy of Viscometer system is $\pm 1 \%$ and repeatability of $\pm 0.2 \%$. Given the direct effect of temperature on fluid viscosity, a circulating temperature control system with an accuracy of $0.1{ }^{\circ} \mathrm{C}$ was used to keep the temperature of the samples constant during the experiment. The temperature bath model LAUDA Alpha RA 8 was utilized for this section. 


\subsection{Measurement of the Flash Point}

Flash Point is a property that determines the stability and safety of fluid at elevated temperatures. The higher flash point measures the limitation on the maximum operating temperature for machines. Measurements were made according to the ASTM D93 standard. The flash point was measured using the close cup method in the Pensky-Martens device. The maximum error is less than two percent. The measurement of flash point can be an efficient way to prevent explosions in storage tanks. According to the standard, $250 \mathrm{~mL}$ of each nano-lubricant sample was prepared to measure the flash point. The following Petrotest comprises a stirrer, thermometer, gas source, a brass cup, heater and temperature control system.

\subsection{Measurement of Pure Point and Freezing Point}

The pour point is the temperature below which the oil loses its functional characteristics and enters the freezing stage. The freezing point is the temperature at which hydrocarbon crystals form when cooling and the oil hardens despite the opacity. This property of the nano lubricant is vital in cold and negative temperatures. These properties of nano lubricants are measured according to the ASTM D97 standard. The cooling system utilized in this research was Protest with a power value of $1300 \mathrm{~W}$. To increase the accuracy of the cloud point, it is necessary to determine the freezing point and then measure the cloud point by decreasing the temperature of the frozen oil. According to evaluation data, the measurement system has an error, less than two percent.

\section{Results}

\subsection{Stability of Nano-Lubricant}

For evaluation of the particle size of nanoparticles, a particle size analyzer, namely, the VASCO ${ }^{\mathrm{TM}}$ nanoparticle size analyzer made by Cordouan technologies company, was used. The test was done two times, after one day and 40 days. According to Stokes' law, the stability of graphene oxide nanosheets in viscous oil is prolonged because of the properties of nanosheets. The nanoparticles have a high specific surface area (SSA) and a planar structure, which reduces the sedimentation velocity. Figure 5 shows the results in detail. The stability of nano lubricants in the long term is a critical feature in practical applications. The average particle size is visible by the device when the laser beam strikes the nanoparticles dispersed in the oil. Data on the nanoparticle size range are according to the Mie scattering theory [25]. The results were measured; the first time was after one day and then after 40 days. The results in Figure 6 are presented. It can be seen, the majority of particles size were in a nanoscale range even after 40 days. In addition, for the second test, the nano lubricant was in a static situation ultimately. The result is acceptable because there is not any agglomeration.

\subsection{The Effect of Temperature and Volume Fraction on Thermal Conductivity}

Figure 7 shows the impact of temperature on the thermal conductivity of base oil and nano lubricant containing graphene oxide in various volume fractions and temperature ranges of 35 to $75{ }^{\circ} \mathrm{C}$. The most remarkable improvement in thermal conductivity is observed at the highest volume fraction and the highest temperature. The results show that with increasing temperature, the thermal conductivity of the base oil decreases, while the thermal conductivity of the nano lubricant raises in higher volume fractions. This increase is more visible at elevated temperatures because, at higher temperatures, the energy level, movement and vibration of molecules nano lubricants will be increased. The process of increasing temperature leads to the loosening of molecular bonds between fluid layers and increases the speed of molecules and displacement at the microscale and is one of the main reasons for increasing the thermal conductivity [26]. The use of solid nanoparticles was a cause of increasing the thermal conductivity in this experiment, with a high surface to volume ratio and thermal conductivity. This feature of nano lubricant can be precious for use in car engines. 


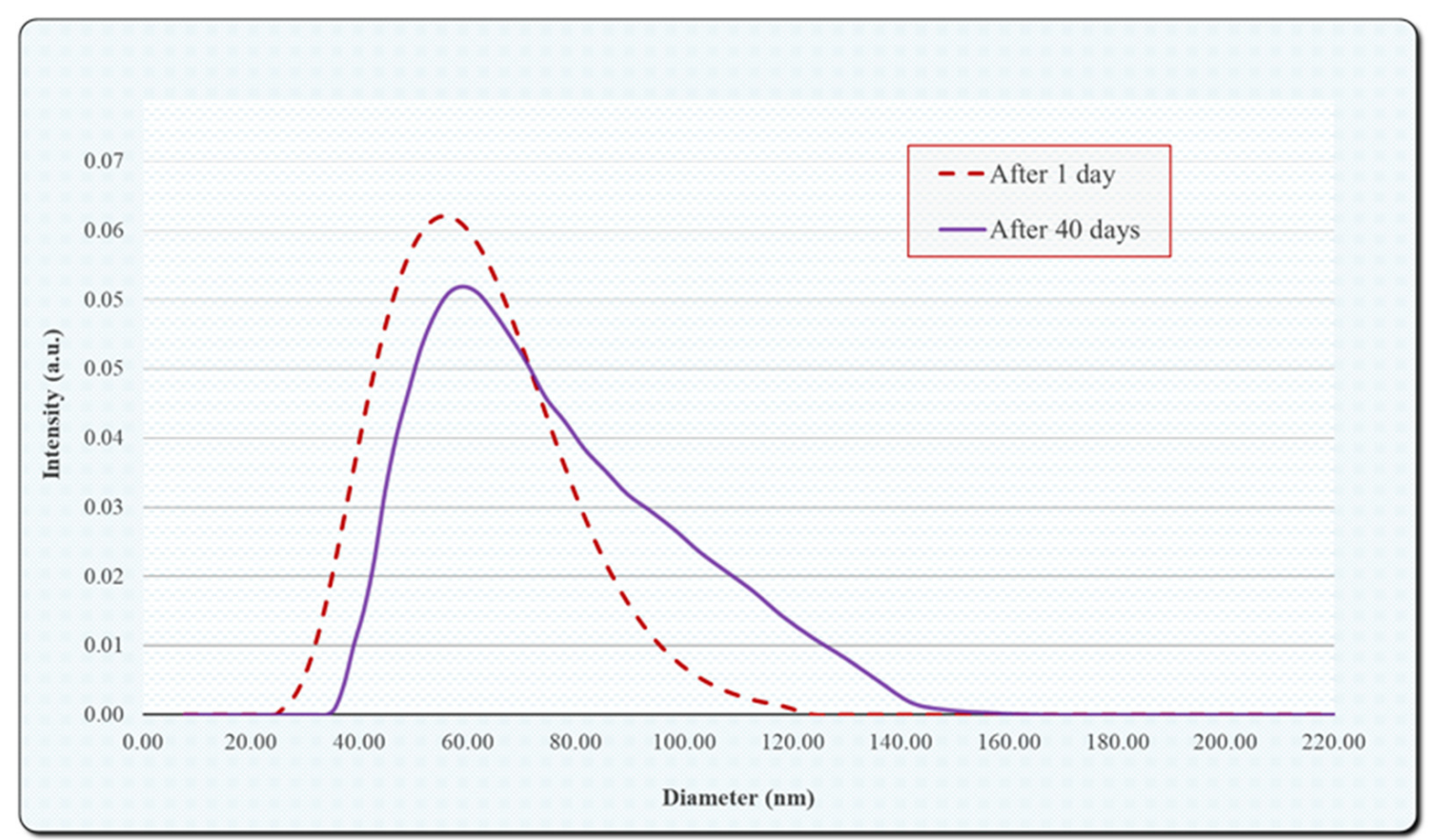

Figure 6. The distribution of graphene oxide nanoparticles in the oil-based at two times.

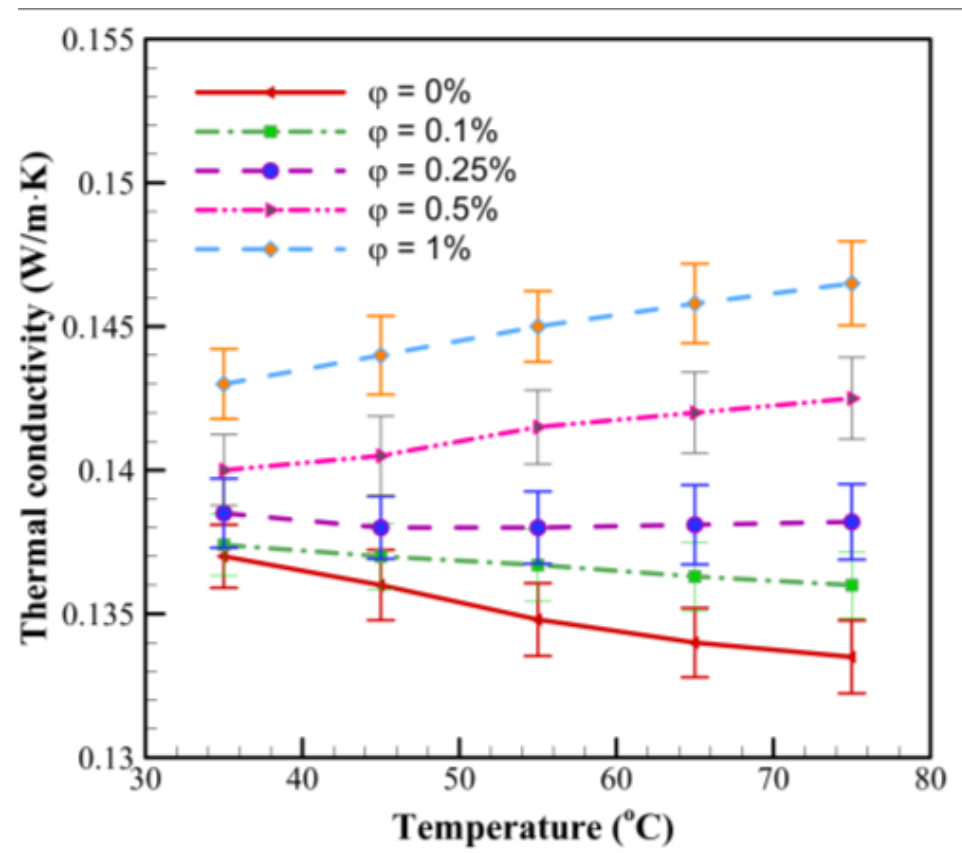

Figure 7. The effect of temperature on the thermal conductivity of nano lubricant in different volume fractions.

The relative thermal conductivity at various temperatures and volume fractions is shown in Figure 8. This parameter is obtained by dividing the thermal conductivity of the nanofluid by the thermal conductivity of the base fluid. According to the results, the rate of thermal conductivity increases with increasing temperature. In this experiment, when the temperature rises, the molecules of the base fluid accelerate at high speeds, which cause the Brownian motion of the solid nanoparticles by accidental collision and impact on the surface of the nanoparticles, thereby increasing the thermal conductivity of the nanofluid $[27,28]$. The maximum improvement of thermal conductivity $(9.73 \%)$ was observed at $75{ }^{\circ} \mathrm{C}$ and a volume fraction of $1 \%$. 


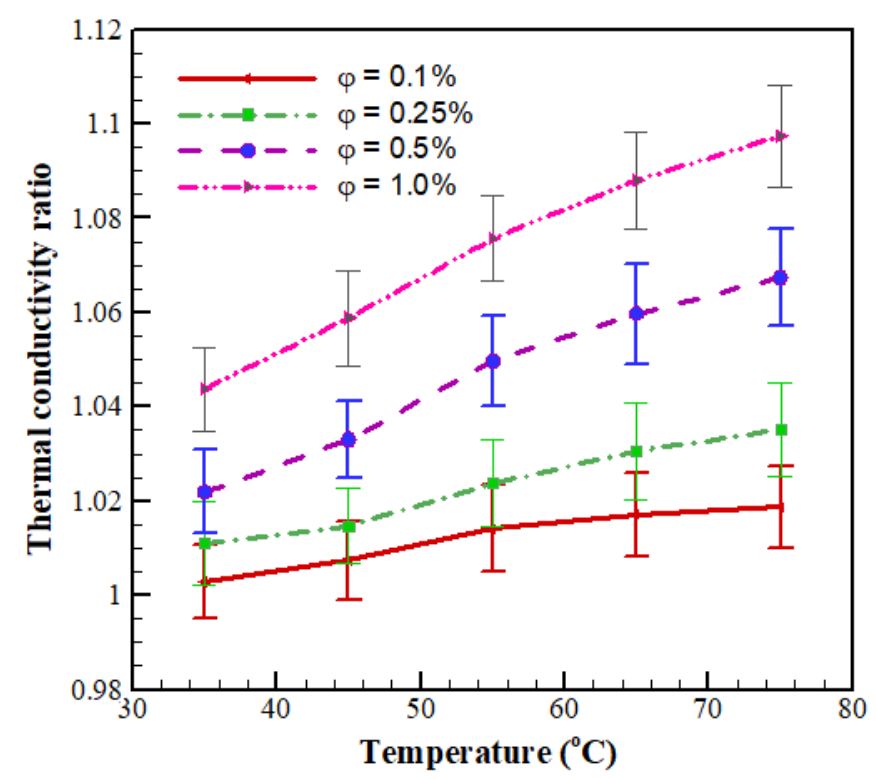

Figure 8. Thermal conductivity ratio of nano lubricant at different temperatures.

In Table 4, a comparison between the present result with previous studies for thermal conductivity is presented. According to the presented results, we can say thermal conductivity enhancement depends on many different parameters such as base fluid, nanomaterial, concentration and the method of nano oil preparation. Some carbon base materials are high thermal conductivity, while their shapes cause increase pumping and electricity power. Conclusively, improving the thermal conductivity of nano oils is very complicated and depending on many parameters.

Table 4. A comparison between this study and previous studies.

\begin{tabular}{|c|c|c|c|c|c|}
\hline Reference & Base-Fluid & Nanoparticles & $\begin{array}{c}\text { Volume Fraction } \\
\text { Range (\%) }\end{array}$ & $\begin{array}{l}\text { Maximum Thermal } \\
\text { Conductivity } \\
\text { Enhancement }(\%)\end{array}$ & $\begin{array}{c}\text { Temperature } \\
\text { Range }\left({ }^{\circ} \mathrm{C}\right)\end{array}$ \\
\hline Present work & SAE 50 & GO & $0.1-1$ & 9.73 at $75^{\circ} \mathrm{C}$ & $35-75$ \\
\hline [29] & SAE 50 engine oil & $\mathrm{ZnO}$ & $0.125-1.5$ & 8.74 at $55^{\circ} \mathrm{C}$ & $25-55$ \\
\hline$[30]$ & Jatropha seed oil & MWCNTs & $0.2-0.8 \mathrm{wt} \%$ & 6.76 at $65^{\circ} \mathrm{C}$ & $25-65$ \\
\hline [20] & SAE 20 W50 & MWCNTs & $0.1-0.5 w t \%$ & 22.7 at $20{ }^{\circ} \mathrm{C}$ & Just 20 \\
\hline$[31]$ & Drilling oil & Bentonite & $1-2$ & 8.05 at $25.6^{\circ} \mathrm{C}$ & $25.6-120.1$ \\
\hline [32] & Vegetable oil & $\mathrm{Cu}$ & $0.1-0.5$ & 13.97 at $30^{\circ} \mathrm{C}$ & Just 30 \\
\hline
\end{tabular}

\subsection{Rheological Behavior of the Nano Lubricant}

In the present study, the rheological behavior of the nano lubricant was investigated. For Newtonian fluids, the relation between the shear rate and shear stress is linear. In order to study the rheological behavior in various volume fractions, the result of shear stress was shown in Figure 9. It is clear that the behavior of nano lubricant is Newtonian and it is similar to the base oil. 

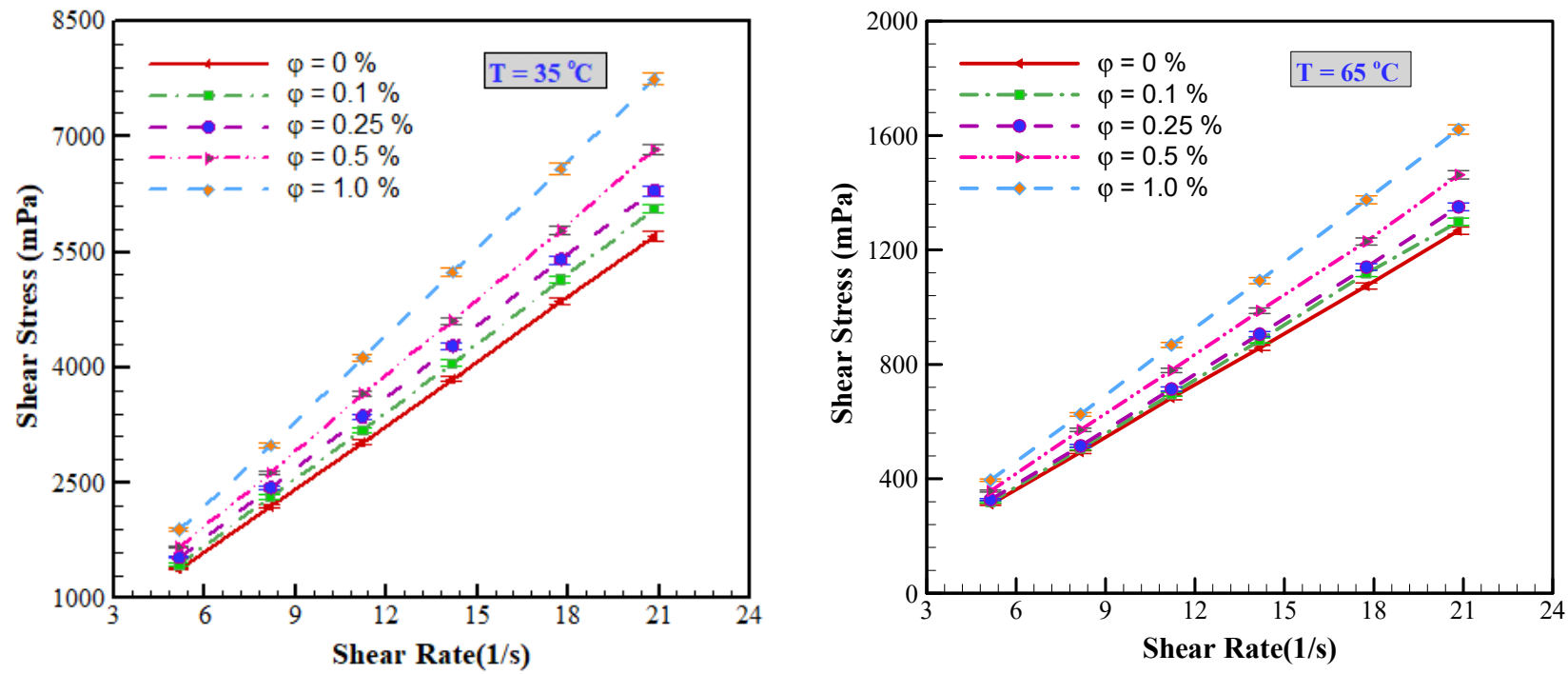

Figure 9. Rheological behavior of nano lubricant at $35^{\circ} \mathrm{C}$ (left) and $65{ }^{\circ} \mathrm{C}$ (right).

Effects of temperature on rheological behavior were investigated and the nano lubricant had Newtonian behavior from $35^{\circ} \mathrm{C}$ to $75^{\circ} \mathrm{C}$. The shear stress has a linear trend in all volume fractions, so only the results for $35^{\circ} \mathrm{C}$ and $65^{\circ} \mathrm{C}$ were presented.

Figure 10 shows that viscosity behavior does not depend on the shear rate in temperatures of $35^{\circ} \mathrm{C}$ and $65^{\circ} \mathrm{C}$ in various volume fractions. The results at different volume fractions show no significant changes in the viscosity behavior of the nano lubricant. However, increasing the temperature from $35^{\circ} \mathrm{C}$ to $65^{\circ} \mathrm{C}$ resulted in decreased viscosity of the nano lubricant.
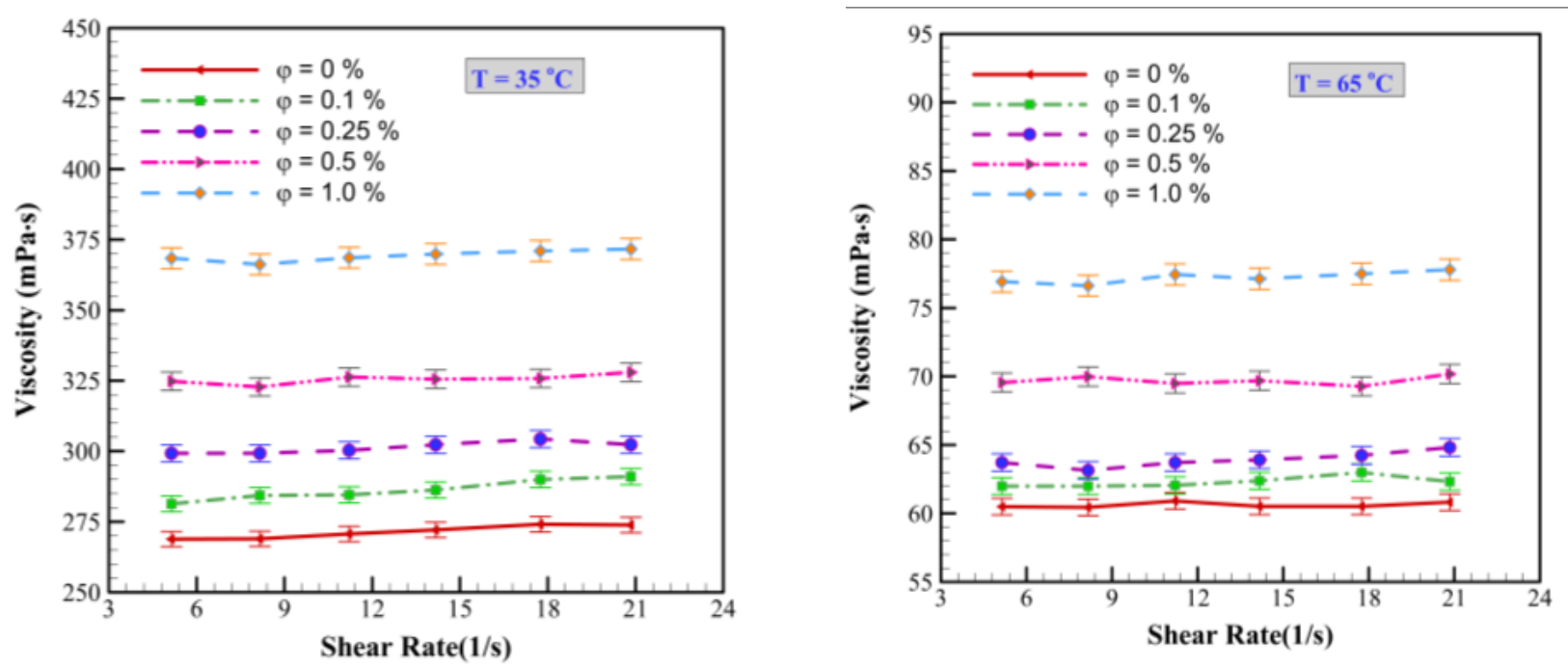

Figure 10. Viscosity behavior of nano lubricant at $35^{\circ} \mathrm{C}($ left $)$ and $65^{\circ} \mathrm{C}$ (right).

\subsection{The Effect of Temperature and Volume Fraction on Viscosity}

Figure 11 depicts the results of the dynamic viscosity of the nano lubricant under the effect of varying volume fractions. These variations are such that in the same volume fraction, an increase in the temperature will remarkably diminish the dynamic viscosity of nano lubricant, which is a leading problem of oils in the industry. In liquid flows, especially oils, molecules can overcome the intermolecular adhesion forces under the influence of more energy with elevated temperature. Consequently, the viscosity decreases under 
increasing temperature. The results show that the viscosity has decreased sharply with an increase in temperature. Increasing the temperature will extend the distance between the molecules of the nanoparticles and the base fluid, thereby diminishing the resistance of the flow layers and the viscosity of the nano lubricant.

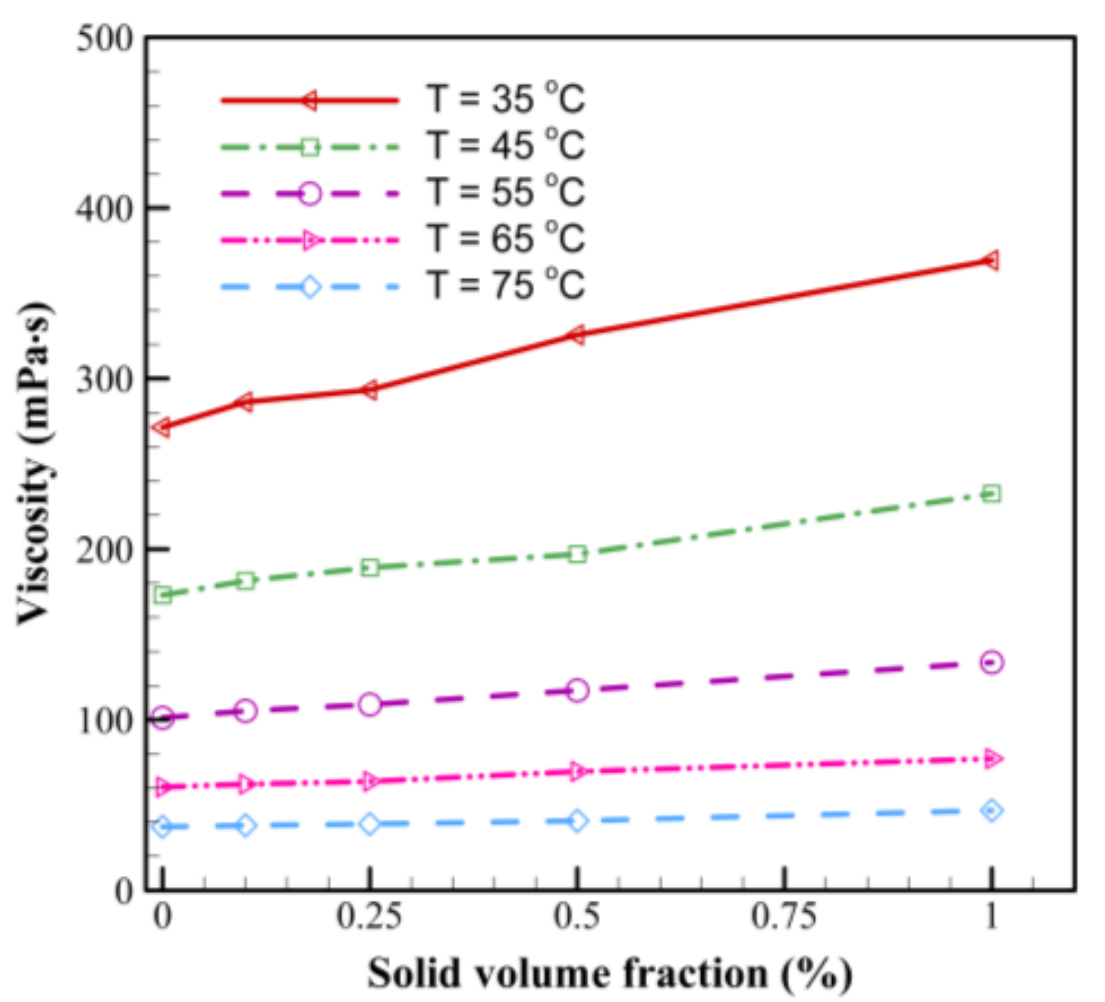

Figure 11. The impact of volume fraction on viscosity of nano lubricant in different temperature.

The highest viscosity is observed at the lowest temperature and the highest volume fraction. At elevated volume fractions and by adding graphene oxide nanoparticles to the base fluid, the flow resistance increases, i.e., the nanoparticles collide more with each other when moving randomly. The viscosity increases by increasing the volume of nanoparticles in a constant quantity of oil and the presence of Van der Waals force. This physical structure of the nanoparticle hinders the layers from moving on each other, consequently raising the viscosity.

According to previous research, we can see that the shape, size and volume fraction of nanoparticles directly affect dynamic viscosity [33,34]. According to the results, graphene oxide nanoparticles improved thermal conductivity of oil, while viscosity behavior did not change.

The viscosity ratio of the nano lubricant to the base oil (relative viscosity of the nano lubricant) is calculated as Equation (2):

$$
\text { RelativeVis cosity }=\frac{\mu_{n f}}{\mu_{b f}}
$$

where $\mu_{n f}$ is the viscosity of the nano lubricant and $\mu_{b f}$ is the viscosity of the base fluid.

Figure 12 shows the ratio of the viscosity of nano-lubricant to the base oil. Variations in the viscosity at lower temperatures are greater than at higher temperatures. The variation decreases with increasing temperature, which is an influential factor in heat and mass transfer applications, such as pumping power and other viscosity issues. Furthermore, the thermal conductivity increases at elevated temperatures. Therefore, the viscosity of nano oil is remarkably sensitive to temperature and volume fraction. Consequently, at low 
concentrations, due to the small volume of nanoparticles in the base oil, variations in the viscosity are not very severe. With increasing the volume fraction, variations in the relative viscosity increase significantly. The highest viscosity ratio 1.36 is observed at $35{ }^{\circ} \mathrm{C}$ and a volume fraction of $1 \%$.

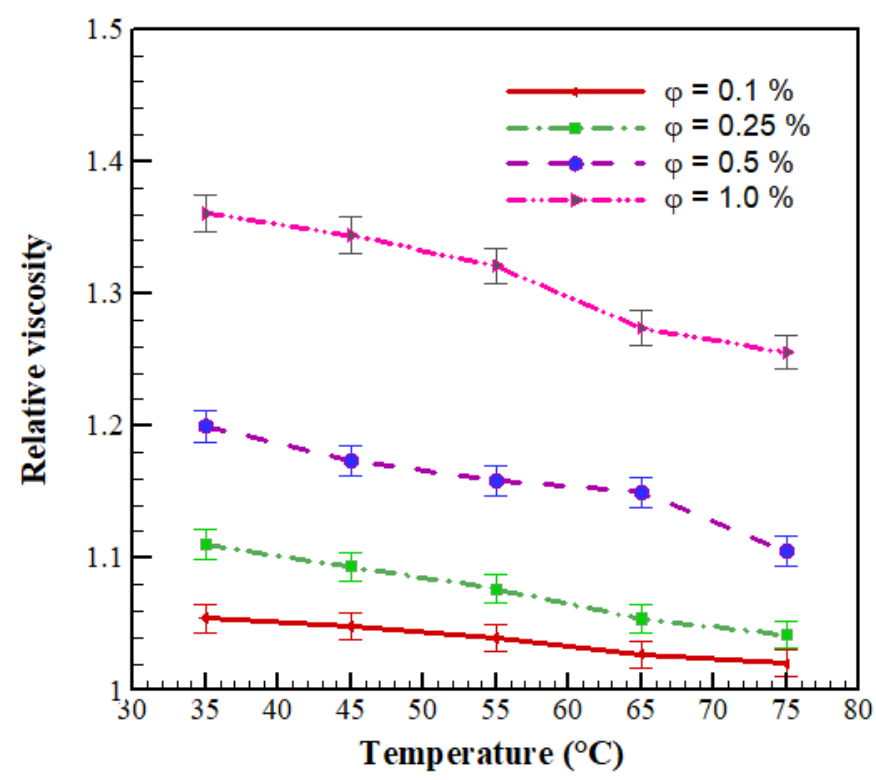

Figure 12. Relative viscosity of nano lubricant in various volume fractions.

\subsection{The Result of the Flash Point}

The flash point is the lowest temperature at which oil turns into steam and forms an explosive mixture with air. At near the flash point, the oil ignites instantly and then goes out. Therefore, the flash point of an oil is a determining parameter for the temperature conditions of the oil. These physical properties are a measure of the degree of ignition and volatility of the oil. The addition of graphene oxide nanoparticles with different volume fractions improves the oil performance for very hot temperatures, which increases the range and operating conditions of the oil. The results are presented based on the volume fraction function in Figure 13. At best, the flash point of the nano lubricant improves by $8 \%$ compared to the base oil. The flash point increases from $235{ }^{\circ} \mathrm{C}$ to $254{ }^{\circ} \mathrm{C}$. The addition of nanoparticles, even with a low volume fraction, can positively influence oil performance.

Deepak and Ram [17] used $\mathrm{TiO} 2$ nanoparticles to increase the flash point of SAE $20 \mathrm{~W} 40$ and virgin coconut oil. Their results have a similar increasing trend compare to our result for flash point. The maximum improvement for their result is greater than $8 \%$ that we could achieve by adding 1\% graphene oxide nanoparticle. In addition, Ettefaghi et al. [20] reported flash point parameter for SAE 20 W50 oil is increased by using MWCNT, the maximum improvement of this property was $6.7 \%$.

\subsection{The Results of Freezing Point and Cloud Point}

The allowable limit for using the oil in extremely cold temperatures is highly critical. In ICEs, the oil and engine temperatures are at their lowest level in the first. In this case, the system is at its lowest temperature and the maximum wear occurs if the lubrication system does not operate properly. The cloud point results, as well as the ratio of variations in the nano lubricant are presented in Figure 14. According to experimental results, when the oil temperature cools and a cloudy layer or halo of paraffin crystals forms inside it, the nano lubricant will perform more efficiently. At this temperature, nano lubricants do not easily lose their fluidity and can yet be applicable. The best conditions are created for the nano lubricant at the highest concentration and the rate of changes increases up to 13.3\%. By comparing the results of this research with the previous one, it seems that Graphene oxide nanoparticles are more efficient; for instance, [19] reported by using 1.5\% $\mathrm{ZnO}$ nanoparticle, 
the cloud point increased about $12 \%$. In addition, we achieved a better result compare to Esmaeilzadeh et al. [31], but they used higher volume fractions and could find lower cloud point.
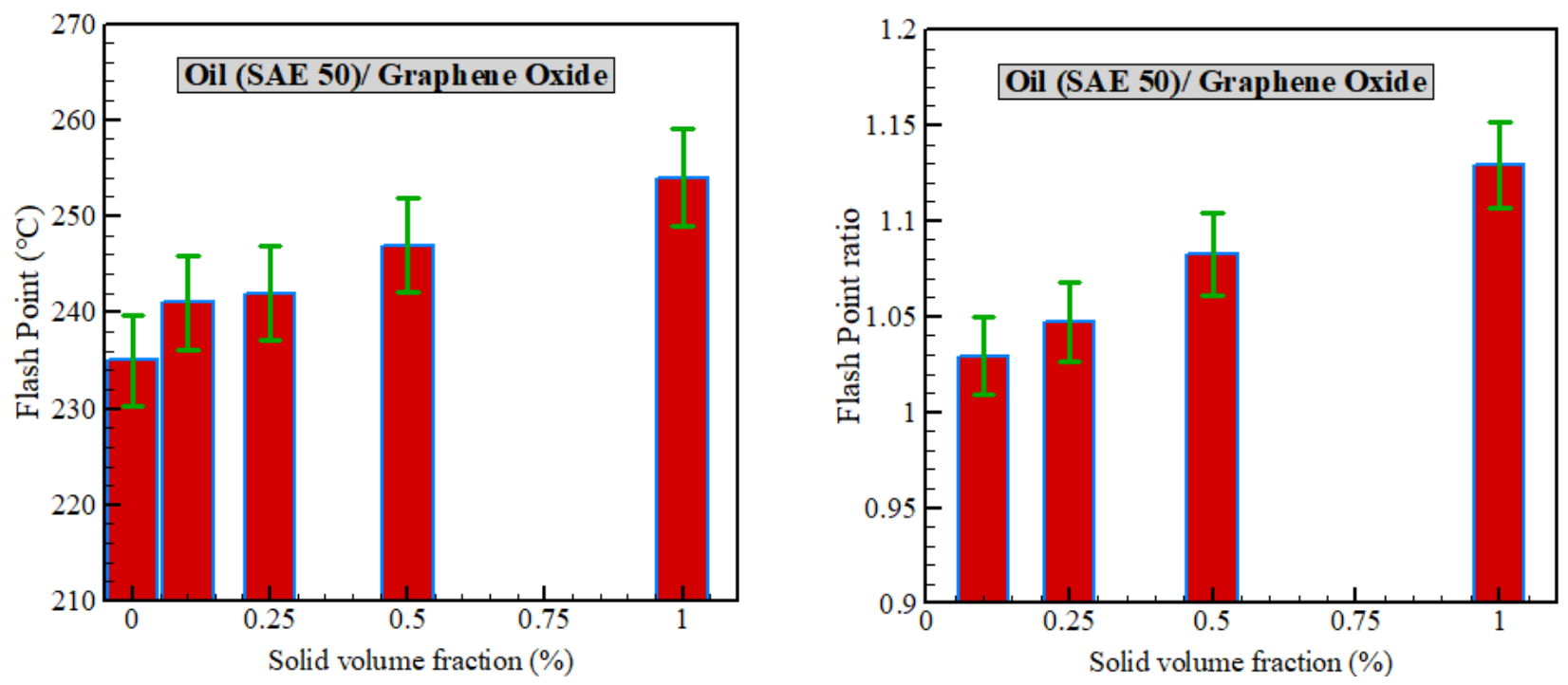

Figure 13. Flash point of the nano lubricant (left) and its ratio (right).
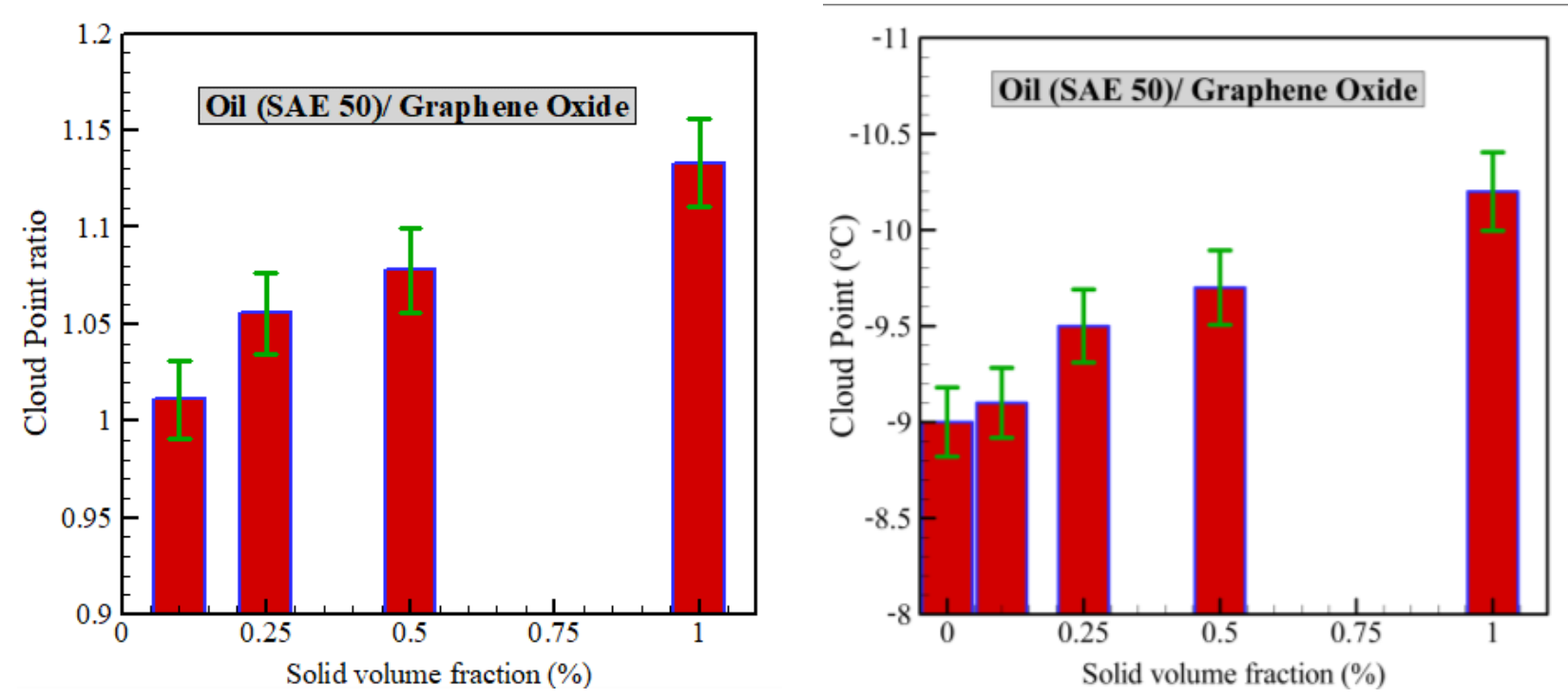

Figure 14. Cloud point of the nano lubricant (left) and its ratio (right).

The freezing point of the nanoparticle was investigated under various volume fractions and the results are shown in Figure 15. The results show that the base oil reaches the freezing point at $-17^{\circ} \mathrm{C}$. By adding nanoparticles to the oil, the freezing temperature of the oil increases. Nanoparticles exert beneficial effects. Positive variations are visible at the base oil, even in very low volume fractions. The lowest freezing temperature is related to the maximum volume fraction and its value is equal to $-19^{\circ} \mathrm{C}$. The results of the ratio of variations in the nano lubricant to the base oil show that the variations in the volume increase more and more with rising the volume fraction. Improving this parameter prevents the oil from freezing in negative weather conditions because the range and conditions of using this nano oil are more than the base oil. 

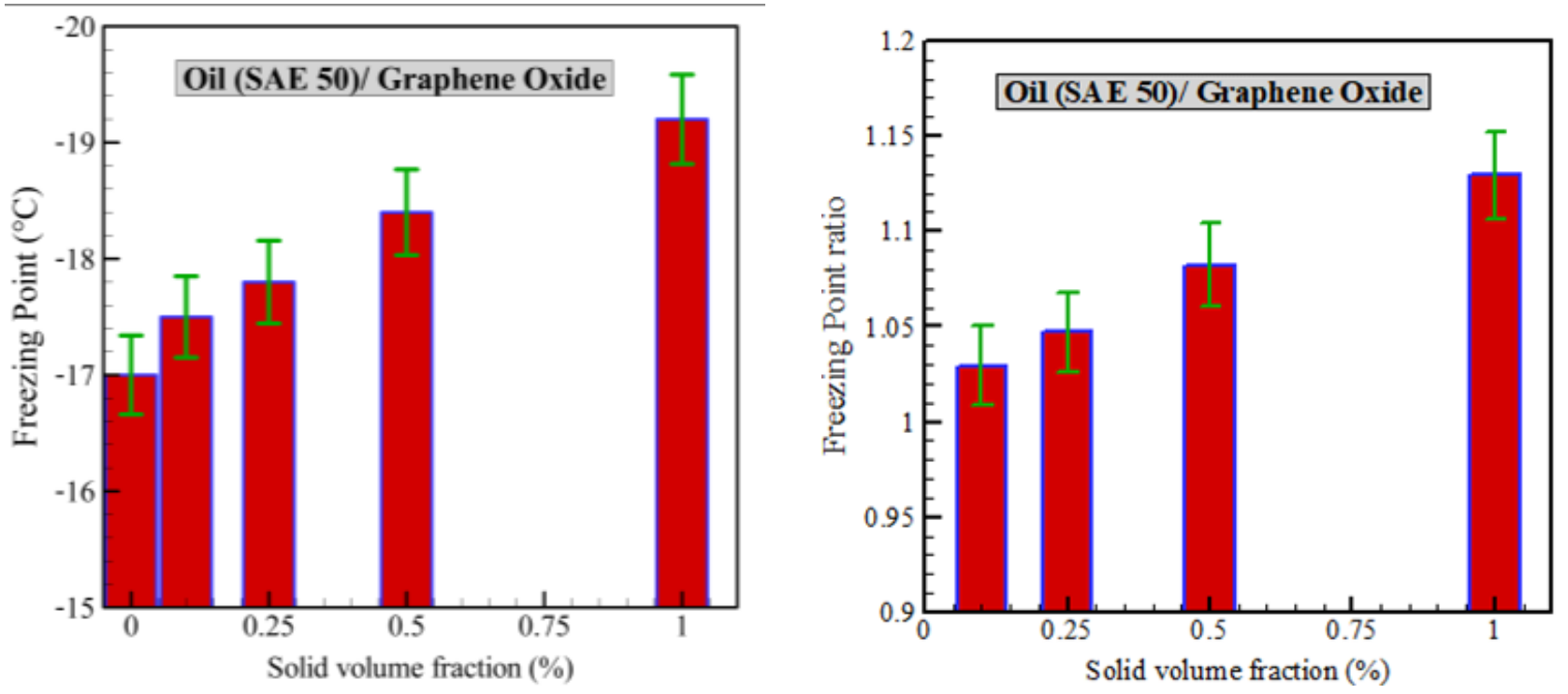

Figure 15. Freezing point of the nano lubricant (left) and its ratio (right).

Ma et al. [19] by using $\mathrm{ZnO}$ nanoparticles could reduce the freezing point to $-20.3{ }^{\circ} \mathrm{C}$, while, in this research, by adding $1 \%$ Graphene oxide, we achieved $-19^{\circ} \mathrm{C}$ for SAE 50 oil. We investigated the stability of the GO/SAE-50 nonlubricated and we realized it has appropriate stability for higher volume fractions while by increasing it, SAE-50 oil will have a higher dynamic viscosity that might will not acceptable for systems wanted using this nano lubricant as a highly efficient alternative oil.

\section{Conclusions}

This study aimed to improve the properties of SAE 50 oil. The effect of using graphene oxide nanoparticles with various volume fractions were investigated. The two-step preparation is a suitable method for this nano lubricant. During the preparing process, the viscosity is decreased at elevated temperatures of the base oil under the conditions of using a magnetic stirrer. In this case, the nanoparticles are fully mixed with the base fluid and undergo homogenization by ultrasonic waves for $60 \mathrm{~min}$. The DLS test evaluated the stability of the nano lubricant at two times, the stability of the nano-lubricant was acceptable.

- The thermal conductivity of nano lubricant increases by temperature and volume fraction. The volume fraction is more effective in improving thermal conductivity than temperature.

- The highest increase in thermal conductivity of nano lubricant $(9.73 \%$ improvement compared to the base oil) was observed at $75{ }^{\circ} \mathrm{C}$ and a volume fraction of $1 \%$.

- The viscosity of the nano lubricant increases due to the use of nanoparticles. These variations will not positively influence the system. In contrast, the viscosity decreases sharply with increasing temperature at all volume fractions. Viscosity fluctuations are considerable and it seems that the increase in viscosity caused by nanoparticles does not have a meaningful effect.

- The viscosity of the nano lubricant was increased to a maximum rate of 1.36 in the volume fraction of $1 \%$. This value was recorded at $35^{\circ} \mathrm{C}$.

- The flash point indicates the performance of the oil in hot seasons and especially at elevated temperatures. By adding nanoparticles, the flash point increased from $235^{\circ} \mathrm{C}$ to $254{ }^{\circ} \mathrm{C}$. This feature improves the oil performance at high temperatures.

- The results of cloud point and freezing point show that the oil performance has improved in cold temperatures. In most cases, the values of cloud point and freezing point improve, respectively, by 13.3 and $12.9 \%$. Under these conditions, this nano lubricant can be used instead of base oil at lower temperatures. 
- Finally, given the thermal properties of this nano lubricant over the base oil, it seems to perform more efficiently under warmer and colder working conditions.

Author Contributions: R.R., in this article working on measurements and experiments activities, validation section, writing - original draft review \& editing. R.C. has made substantial contributions to the work; project administration, analysis, interpretation of data, methodology, and software. We would like to express the gratitude to the anonymous reviewers for their beneficial suggestions and comments that helped us to improve our work. Both authors have read and agreed to the published version of the manuscript.

Funding: This research received no external funding.

Institutional Review Board Statement: In this research, there was not any part of the study involving humans or animals.

Informed Consent Statement: This study is not involving humans.

Data Availability Statement: This experimental research, especially to measure and investigate the presented data, using an advanced nanotechnology laboratory in the Islamic Azad University Najafabad Branch and two individual research centers.

Conflicts of Interest: The authors declare no conflict of interest.

\section{References}

1. Shahnazar, S.; Bagheri, S.; Hamid, S.B.A. Enhancing lubricant properties by nanoparticle additives. Int. J. Hydrog. Energy 2016, 41, 3153-3170. [CrossRef]

2. Singh, Y.; Negi, P.; Badhotiya, G.K. Friction and wear analysis of TiO2 particles blended with Sal oil. Mater. Today Proc. 2021. [CrossRef]

3. Hamze, S.; Cabaleiro, D.; Estellé, P. Graphene-based nanofluids: A comprehensive review about rheological behavior and dynamic viscosity. J. Mol. Liq. 2020, 325, 115207. [CrossRef]

4. ShashaVali, S.; Patil, A. Experimental investigation of tribological properties of TiO2 nanoparticles in engine oil. Mater. Today Proc. 2021. [CrossRef]

5. Du, C.; Nguyen, Q.; Malekahmadi, O.; Mardani, A.; Jokar, Z.; Babadi, E.; D'Orazio, A.; Karimipour, A.; Li, Z.; Bach, Q.V. Thermal conductivity enhancement of nanofluid by adding multiwalled carbon nanotubes: Characterization and numerical modeling patterns. Math. Methods Appl. Sci. 2020. [CrossRef]

6. Huo, M.; Wu, H.; Xie, H.; Zhao, J.; Su, G.; Jia, F.; Li, Z.; Lin, F.; Li, S.; Zhang, H. Understanding the role of water-based nanolubricants in micro flexible rolling of aluminium. Tribol. Int. 2020, 151, 106378. [CrossRef]

7. Wang, B.; Wang, X.; Lou, W.; Hao, J. Thermal conductivity and rheological properties of graphite/oil nanofluids. Colloids Surf. A Phys. Eng. Asp. 2012, 414, 125-131. [CrossRef]

8. Pico, D.F.M.; da Silva, L.R.R.; Mendoza, O.S.H.; Filho, E.P.B. Experimental study on thermal and tribological performance of diamond nanolubricants applied to a refrigeration system using R32. Int. J. Heat Mass Transf. 2020, 152, 119493. [CrossRef]

9. Vakili-Nezhaad, G.; Dorany, A. Investigation of the effect of multiwalled carbon nanotubes on the viscosity index of lube oil cuts. Chem. Eng. Commun. 2009, 196, 997-1007. [CrossRef]

10. Ali, M.K.A.; Xianjun, H.; Abdelkareem, M.A.; Gulzar, M.; Elsheikh, A. Novel approach of the graphene nanolubricant for energy saving via anti-friction/wear in automobile engines. Tribol. Int. 2018, 124, 209-229. [CrossRef]

11. Hatami, M.; Hasanpour, M.; Jing, D. Recent developments of nanoparticles additives to the consumables liquids in internal combustion engines: Part II: Nano-lubricants. J. Mol. Liq. 2020, 319, 114156. [CrossRef]

12. Gong, H.; Yu, C.; Zhang, L.; Xie, G.; Guo, D.; Luo, J. Intelligent lubricating materials: A review. Compos. Part B Eng. 2020, 202, 108450. [CrossRef]

13. Owuna, F. Stability of vegetable based oils used in the formulation of ecofriendly lubricants-A review. Egypt. J. Pet. 2020, 29, 251-256. [CrossRef]

14. Li, Z.; D'Orazio, A.; Karimipour, A.; Bach, Q.-V. Thermo-hydraulic performance of a lubricant containing zinc oxide nano-particles: A two-phase oil. J. Energy Resour. Technol. 2020, 142. [CrossRef]

15. Zheng, Y.; Wang, S.; D'Orazio, A.; Karimipour, A.; Afrand, M. Forecasting and optimization of the viscosity of nano-oil containing zinc oxide nanoparticles using the response surface method and sensitivity analysis. J. Energy Resour. Technol. 2020, 142, 1-8. [CrossRef]

16. Timofeeva, E.V.; Moravek, M.R.; Singh, D. Improving the heat transfer efficiency of synthetic oil with silica nanoparticles. J. Colloid Interface Sci. 2011, 364, 71-79. [CrossRef]

17. Neha Deepak, S.; Nathi Ram, C. Physio-chemical study of traditional lubricant SAE 20 W40 and virgin coconut oil using TiO2 nano-additives. Mater. Today Proc. 2021, 42, 1024-1029. [CrossRef] 
18. Ilyas, S.U.; Pendyala, R.; Narahari, M.; Susin, L. Stability, rheology and thermal analysis of functionalized alumina-thermal oil-based nanofluids for advanced cooling systems. Energy Convers. Manag. 2017, 142, 215-229. [CrossRef]

19. Ma, J.; Shahsavar, A.; Al-Rashed, A.A.A.A.; Karimipour, A.; Yarmand, H.; Rostami, S. Viscosity, cloud point, freezing point and flash point of zinc oxide/SAE50 nanolubricant. J. Mol. Liq. 2020, 298, 112045. [CrossRef]

20. Ettefaghi, E.-o.-I.; Ahmadi, H.; Rashidi, A.; Nouralishahi, A.; Mohtasebi, S.S. Preparation and thermal properties of oil-based nanofluid from multi-walled carbon nanotubes and engine oil as nano-lubricant. Int. Commun. Heat Mass Transf. 2013, 46, 142-147. [CrossRef]

21. Marcano, D.C.; Kosynkin, D.V.; Berlin, J.M.; Sinitskii, A.; Sun, Z.; Slesarev, A.; Alemany, L.B.; Lu, W.; Tour, J.M. Improved synthesis of graphene oxide. ACS Nano 2010, 4, 4806-4814. [CrossRef] [PubMed]

22. Eastman, J.A.; Choi, S.; Li, S.; Yu, W.; Thompson, L. Anomalously increased effective thermal conductivities of ethylene glycol-based nanofluids containing copper nanoparticles. Appl. Phys. Lett. 2001, 78, 718-720. [CrossRef]

23. Ranjbarzadeh, R.; Akhgar, A.; Musivand, S.; Afrand, M. Effects of graphene oxide-silicon oxide hybrid nanomaterials on rheological behavior of water at various time durations and temperatures: Synthesis, preparation and stability. Powder Technol. 2018, 335, 375-387. [CrossRef]

24. Sadeghinezhad, E.; Mehrali, M.; Saidur, R.; Mehrali, M.; Latibari, S.T.; Akhiani, A.R.; Metselaar, H.S.C. A comprehensive review on graphene nanofluids: Recent research, development and applications. Energy Convers. Manag. 2016, 111, 466-487. [CrossRef]

25. Newton, R.G. Scattering Theory of Waves and Particles; Springer Science \& Business Media: Berlin/Heidelberg, Germany, 2013.

26. Chon, C.; Kihm, K. Thermal conductivity enhancement of nanofluids by Brownian motion. Trans. Am. Soc. Mech. Eng. J. Heat Transf. 2005, 127, 810. [CrossRef]

27. Yang, B. Thermal conductivity equations based on Brownian motion in suspensions of nanoparticles (nanofluids). J. Heat Transf. 2008, 130. [CrossRef]

28. Yu, W.; Choi, S. The role of interfacial layers in the enhanced thermal conductivity of nanofluids: A renovated Maxwell model. J. Nanoparticle Res. 2003, 5, 167-171. [CrossRef]

29. Yang, L.; Mao, M.; Huang, J.-n.; Ji, W. Enhancing the thermal conductivity of SAE 50 engine oil by adding zinc oxide nano-powder: An experimental study. Powder Technol. 2019, 356, 335-341. [CrossRef]

30. Rehman, W.U.; Merican, Z.M.A.; Bhat, A.H.; Hoe, B.G.; Sulaimon, A.A.; Akbarzadeh, O.; Khan, M.S.; Mukhtar, A.; Saqib, S.; Hameed, A.; et al. Synthesis, characterization, stability and thermal conductivity of multi-walled carbon nanotubes (MWCNTs) and eco-friendly jatropha seed oil based nanofluid: An experimental investigation and modeling approach. J. Mol. Liq. 2019, 293, 111534. [CrossRef]

31. Esmaeilzadeh, F.; Teja, A.S.; Bakhtyari, A. The thermal conductivity, viscosity, and cloud points of bentonite nanofluids with n-pentadecane as the base fluid. J. Mol. Liq. 2020, 300, 112307. [CrossRef]

32. Kumar Yadav, S.; Vasu, V.; Kumar Paliwal, U. Experimental Study on Thermo-physical Properties of Nano-fluids based on Copper Nanoparticles. Mater. Today Proc. 2019, 18, 525-532. [CrossRef]

33. Mousavi, S.B.; Heris, S.Z.; Estellé, P. Viscosity, tribological and physicochemical features of ZnO and MoS2 diesel oil-based nanofluids: An experimental study. Fuel 2021, 293, 120481. [CrossRef]

34. Motahari, K.; Moghaddam, M.A.; Moradian, M. Experimental investigation and development of new correlation for influences of temperature and concentration on dynamic viscosity of $\mathrm{MWCNT}^{-\mathrm{SiO}_{2}}$ (20-80)/20W50 hybrid nano-lubricant. Chin. J. Chem. Eng. 2018, 26, 152-158. [CrossRef] 